\section{Erratum to: Math at the Met}

The online version of the original article can be found under doi:10.1007/s00283-015-9571-8.

\section{Erratum to: The Mathematical Intelligencer DOI 10.1007/s00283-015-9571-8 Published 37-3 page 41 The Mathematical Tourist- Dirk Huylebrouck, Editor}

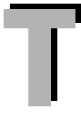
he following photo credit to The Metropolitan Museum of Art was inadvertently omitted in the captions of Figures 15, 16, and 18: Image copyright (C) The Metropolitan Museum of Art. Image source: Art Resource, NY.

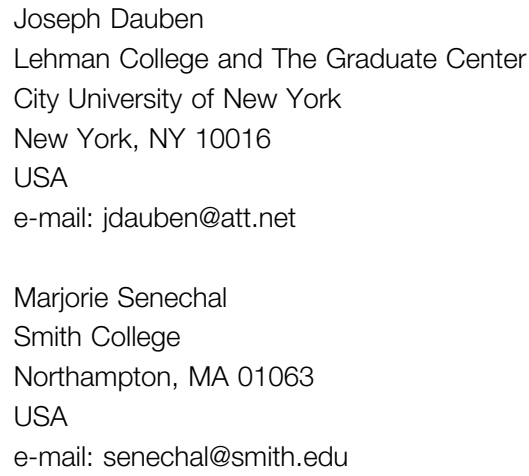

